\title{
Revivalisme Kebudayaan Jawa Mangkunegara VIII di Era Republik
}

\author{
Adi Putra Surya Wardhana ${ }^{1}$, Titis Srimuda Pitana ${ }^{2}$, Susanto ${ }^{3}$ \\ ${ }^{1}$ Kajian Budaya, Pascasarjana (PPs), Universitas Sebelas Maret Surakarta \\ ${ }^{2}$ Program Studi Arsitektur, Fakultas Teknik, Universitas Sebelas Maret Surakarta \\ ${ }^{3}$ Program Studi Ilmu Sejarah, Fakultas Ilmu Budaya, Universitas Sebelas Maret Surakarta
}

adiputra@student.uns.ac.id

\begin{abstract}
Tulisan ini bertujuan untuk membedah relasi kuasa-pengetahuan di balik diskursus revivalisme kebudayaan Jawa Mangkunegara VIII. Mangkunegaran adalah sebuah istana yang pernah menjadi salah satu pusat pemerintahan Jawa pada masa kolonial. Mangkunegaran dipimpin oleh seorang Mangkunegara. Pasca kemerdekaan, Mangkunegaran tidak lebih dari sebuah bangunan yang menyimpan kisah-kisah kejayaan para leluhur. Mangkunegara VIII adalah pemimpin Mangkunegaraan pada saat itu. Ia harus menghadapi berbagai macam tekanan sosial, politik, dan ekonomi. Ia kehilangan kedudukan sebagai kepala pemerintahan Mangkunegaran. Oleh sebab itu, ia membutuhkan sesuatu untuk memulihkan kehormatannya, yaitu kebudayaan Jawa. Ada tiga pokok bahasan yang dikaji oleh tulisan ini. (1) Bagaimana bentuk wacana revivalisme kebudayaan Jawa Mangkunegara VIII pada era Republik? (2) Bagaimana fungsi wacana revivalisme kebudayaan Jawa Mangkunegara VIII? (3) Bagaimana makna wacana revivalisme kebudayaan Jawa Mangkunegara VIII? Wacana revivalisme kebudayaan Jawa Mangkunegara VIII berbentuk klaim bahwa ia adalah pengayom kebudayaan Jawa. Mangkunegaran merupakan pusat pelestarian kebudayaan Jawa. Mangkunegaran mempertunjukkan kesenian-kesenian khasnya kepada khalayak umum, para pejabat, dan tamu-tamu asing. Mangkunegaran menjadi pusat untuk menggali kesenian-kesenian khasnya yang pernah mati suri. Fungsi dari wacana ini adalah untuk memperoleh kehormatan dari abdi dalem, masyarakat, dan petinggi republik dalam bidang kebudayaan. Makna dari wacana ini bagi mereka yang terhegemoni adalah anggapan bahwa Mangkunegaran menyimpan harta dan warisan budaya yang adiluhung dari para leluhur.
\end{abstract}

Kata kunci : mangkunegara viii, revivalisme kebudayaan, kebudayaan jawa, diskursus

\section{Mangkunegara VIII's Javanese Cultural Revivalism in the Republican Era}

This paper aims to examine the power-knowledge relation behind the discourse of Mangkunegara VIII's Javanese cultural revivalism in the Republican era. Mangkunegaran is a palace that had been one of the centers of Javanese government in the colonial period. Mangkunegaran is led by a Mangkunegara. Post-Indonesian independence, Mangkunegaran is nothing more than a building that stores many stories of the glory of the ancestors. Mangkunegara VIII was the leader of Mangkunegaraan at the time. He must face various kinds of social, political and economic pressure. He lost his position as head of the Mangkunegaran government. Therefore, he needed something to restore his honor, i.e Javanese culture. There are three topics discussed in this paper. (1) What are the forms of the Javanese cultural revivalism of Mangkunegara VIII in the Republican era? (2) How is the function of the discourse of Javanese cultural revivalism of Mangkunegara VIII? (3) What is the meaning of discourse of Javanese cultural revivalism of Mangkunegara VIII? This paper uses Michel Foucault's Discourse approach to expose the Javanese cultural revivalism of Mangkunegara VIII. He built the knowledge that he was a protector of Javanese culture. Mangkunegaran is the center of Javanese culture. Mangkunegaran preserves creates, creates art, demonstrates, and revives its distinctive arts that apparent death. This is the form of the ceremony of Javanese Mangkunegara VIII cultural revivalism. The function of this discourse is to get the honor of being the protector and preserver of Javanese culture from the subject. The meaning of this discourse for those who are hegemonized is the assumption that Mangkunegaran keeps valuable wealth and cultural heritage from the ancestors.

Keywords : Mangkunegara VIII, Cultural Revivalism, Javanese Culture, Discourse

Proses Review : 1 - 10 Februari 2019, Dinyatakan Lolos: 13 Februari 2019 


\section{PENDAHULUAN}

Seringkali terminologi revivalisme dihubungkan dengan gerakan keagamaan karena istilah revival berasal dari sejarah tradisi Kekristenan yang dimaknai sebagai gerakan kebangkitan atau kebangunan rohani (Mudzakkir, 2011). Ada berbagai macam penelitian yang mengkaji tentang gerakan revival Kristen seperti yang diteliti Maxwell (2018), Ritchie (2014), McGregor (2012), Meyer (2011), Curtis (2011), Müller \& Neundorf (2012), dan Greeley (1994). Revivalisme dianggap lebih daripada fenomena tonggak sejarah perkembangan agama yang dipengaruhi aspek sosial, budaya, ekonomi, dan politik (Mode, 1921; Al-Azmeh, 1991; Panikkar, 2003). Setiap daerah pernah mengalami revival dalam keagamaan (Northmore-Ball \& Evans, 2016).

Menurut Evers \& Siddique (1993), revivalisme adalah proses kontemporerisasi masa lalu sehingga lebih relevan dengan masa kekinian. Ini berarti, revivalisme tidak melulu berkaitan dengan praktik keagamaan. Oleh sebab itu, revivalisme juga dapat berhubungan dengan konteks kebudayaan. Davidson \& Henley (ed) (2007) mengatakan bahwa revivalisme berkaitan erat dengan dinamika kebudayaan, tradisi, dan adat yang lahir karena tekanan-tekanan politik, ekonomi, dan modernitas. Menurut Siburian (2011), modernisasi dan rasionalisasi memberi tekanan sosial-ekonomi yang dirasakan oleh kalangan menengah perkotaan sehingga perlu diturunkan melalui revivalisme. Artinya, revivalisme kebudayaan muncul sebagai tanggapan terhadap proses sosial, ekonomi, budaya, dan politik yang mendesak eksistensi suatu entitas.

Misalnya saja dalam konteks kebudayaan Jawa, ilmuwan kolonial seperti P.J Veth dan Raffles menganggapnya adiluhung meski ada maksud tertentu di balik wacana (Fakih, 2014). Relasi kompleks antara kolonialisme, modernisme, kapitalisme, Islamisme, dan Jawanisme pernah menjadi pemantik revivalisme kebudayaan Jawa pada awal abad ke-20. Pada masa itu, revivalisme kebudayaan Jawa memiliki relasi dengan kemunculan nasionalisme Jawa yang disebabkan oleh bahasa dan dominasi kolonial. Artinya, wacana ini lahir untuk menanggapi tekanan.

Tekanan yang dihadapi oleh Mangkunegaran pasca kemerdekaan Indonesia (1945) adalah salah satu penyebab munculnya wacana revivalisme kebudayaan Jawa. Tekanan-tekanan disebabkan oleh perubahan tata kenegaraan, tuntutan reformasi birokrasi oleh elit istana golongan moderat, konflik antar golongan elit istana, gerakan anti swapraja, nasionalisasi aset, stereotipe pro Belanda, dan kegamangan Pengageng Pura. Otoritas politik Mangkunegara VIII sebagai pemimpin Daerah Istimewa Mangkunegaran (DIM) dikurangi sedikit demi sedikit pasca kemerdekaan.

Penetapan Pemerintah No. 16/SD Tahun 1946 menyatakan bahwa "segenap pegawai, bangunan, dan peralatan yang termasuk kekuasaan jabatan-jabatan tersebut diserahkan kepada pemegang jabatan termaksud", yaitu pemerintah keresidenan Surakarta (Penetapan Pemerintah 1946 No. 16/S.D tentang penghapusan Komisaris Tinggi untuk Daerah Istimewa Surakarta dan Yogyakarta dan pembentukan Keresidenan Surakarta dan Kota Surakarta, 1946). Artinya, Mangkunegara VIII kehilangan otoritasnya untuk menjalankan sebuah pemerintahan karena seluruh pegawai, bangunan, dan peralatan diambil alih oleh pemerintah Republik.

Kemudian, Undang-undang Nomor 16 Tahun 1947 tentang haminte Kota Surakarta memuat tentang kewilayahan, yaitu sebagian Kabupaten Kota Kasunanan dan sebagaian Kabupaten Kota Mangkunegaran (Undang-undang Nomor 16 Tahun 1947 tentang Pembentukan Haminte-Kota Surakarta, 1947). Pada 4 Juli 1950, pemerintah Republik juga mengeluarkan Undang-undang Nomor 10 Tahun 1950 tentang pembentukan Provinsi Jawa Tengah yang meniadakan daerah Keresidenan Surakarta (Undang-undang Nomor 10 Tahun 1950 tentang Pembentukan Propinsi Djawa Tengah, 1950). Peraturan-peraturan ini mendesak Mangkunegara VIII. Dengan demikian, DIM hilang secara otomatis. Mangkunegara VIII hanya memiliki otoritas sebagai pengageng pura, pengayom budaya, dan kepala trah Mangkunegaran. Desakan-desakan ini yang membuat Mangkunegara VIII membahasakan revivalisme kebudayaan Jawa dan mengukuhkan diri sebagai pengayom budaya. Oleh sebab itu, tulisan ini mencoba untuk menjawab beberapa permasalah. (1) Bagaimana bentuk wacana revivalisme kebudayaan Jawa Mangkunegara VIII pada era Republik? (2) Bagaimana fungsi wacana revivalisme kebudayaan Jawa Mangkunegara VIII? (3) Bagaimana makna wacana revivalisme kebudayaan Jawa Mangkunegara VIII? Tujuan utama tulisan ini adalah mendedah praktik dan rekasi kuasa-pengetahuan di balik wacana revivalisme kebudayaan Jawa Mangkunegara VIII pada era Republik.

\section{METODE PENELITIAN}

Tulisan ini disusun melalui pengumpulan sumber, kritik sumber, interpretasi, dan penulisan hasil penelitian dalam lembar kerja. Penelitian ini menggunakan analisis diskursus sebagai cara-cara tertentu untuk memahami segala gejala kultural yang merupakan teks. Menurut Ratna (2010: 396-400), gejala kultural perlu dianalisis sebagai suatu produksi diskursus. 
Kehidupan ini merupakan sebuah diskurus, bahkan kehidupan itu sendiri adalah diskursus. Melalui konteks global dan lokalnya, diskursus dipelajari sebagai bagian konstitutif dari konteks seperti penempatan-penempatan, pengetahuan sosial yang relevan, struktur kelembagaan atau organisasional, para partisipan dan peran komunikasi dan sosial, tujuan-tujuan, norma-norma dan nilai-nilai (Barker \& Galasiński, 2001). Diskursus dapat pula dimanfaatkan untuk mendedah topik-topik sejarah dan politik sebagai teks. Pendekatan historis diskursus digunakan untuk menyingkap dimensi sejarah dari aksi-aksi dan peristiwa-peristiwa diskursif dengan cara mengintegrasi pengetahuan-pengetahuan tentang sumber-sumber sejarah dan latar kondisi sosial-politik secara interteks dan interdiskursif (Weiss \& Wodak, 2003: 22). Lalu, apa yang dimaksud dengan diskursus?

Sebagaimana postmodernisme menyatakan bahwa tidak ada kebenaran tunggal, terminologi diskursus memiliki banyak definisi karena digunakan secara berbeda oleh peneliti dan latar budaya akademik yang berbeda (Weiss \& Wodak, 2003: 49). Menurut Foucault (2012: 55-65, 386-387), diskursus merupakan seperangkat pernyataan yang diatur, diseleksi, dibangun, disebarluaskan, dan disertai praktik sosial berdasarkan regulasi tertentu yang mengandung jaringan kekuasaan pada semua unsur tersebut sehingga membahasakan suatu kebenaran pada periode tertentu. Hasrat dan kekuasaan selalu ada di balik kelahiran diskursus. Relasi-relasi yang menghubungkan pernyataan-pernyataan yang saling berkaitan sehingga mempengaruhi diskursus dalam kurun waktu tertentu disebut dengan formasi diskursif (diskursus-diskursus). Berbagai macam peristiwa diskursif terekam dalam berbagai sumber data yang terdiri dari arsip, surat kabar, surat, pamflet, buku, karya dan praktik budaya.

\section{MENJADI PENGAGENG PURA MANGKU- NEGARAN: SEBUAH GENEALOGI}

Latar belakang Mangkunegara VIII, ideologi, spiritualitas, pengalaman hidup, pengetahuan, pandangan tentang dunia, tekanan-tekanan dari luar, proses sosial, dan praktik-praktik budaya perlu diteliti secara arkeologis. Arkeologi digunakan untuk menentukan dan mendefinisikan diskursus yang dipraktikkan berdasarkan aturan-aturan tertentu, memperlihatkan cara-cara diskursus membentuk aturan-aturan yang ditetapkan, membuntuti diskursus yang dibatasi garis batas eksteriornya, menentukan aturan-aturan dalam praktik-praktif diskursif, dan berwujud diskripsi sistematis terhadap objek diskursus (Foucault, 2012: 250-252). Arkeologi adalah sumber teks dari sebuah ide tentang diskursus konstitutif (Armstrong, 2015). Genealogi digunakan untuk menelisik terbentukn- ya rangkaian-rangkaian diskursus, patokan-patokan umum, dan kondisi-kondisi yang terjadi dalam setiap proses perkembangan dan variasinya. Genealogi mengurai formasi efektif diskursus dan menelusuri kekuasaan afirmasinya (Foucault, 2012: 422-425). Kali (2013: 40) memahami genealogi Foucault sebagai pendekatan untuk mendiskripsikan sejarah episteme yang berhubungan dengan kekuasaan dengan efek yang muncul terhadap episteme. Ini berbeda dengan arkeologi yang menitikberatkan pada pembongkaran praktik diskursif.

Menyingkap formasi diskursif sangat penting untuk menggambarkan adanya diskursus revivalisme kebudayaan Jawa, pembentukannya, wujudnya, penyebarannya, dan respon terhadap diskursus. Sebagaimana pendapat Foucault (2012: 96), pencarian terhadap jalinan yang renggang dari kata-kata dan benda-benda, dan kesesuaian antara formasi diskursif dengan sekelompok aturan yang timbul, penting untuk menganalisis diskursus. Oleh sebab itu, subbab ini menjelaskan tentang riwayat Mangkungara VIII yang dianalisis secara arkeologis dan genealogis.

Sebelum bertahta, Mangkunegara VIII memiliki nama Bendara Raden Mas (BRM) Hamidjojo Saroso (Pengetan 40 Tahun Jumenengdhalem S.I.J. Mangkoenagoro VIII Hing Surakarta Surya kaping 19 Juli 1984 ing Pandhapi Ageng Mangkunegaran, 1984: 29). Ia adalah anak ketiga dan anak laki-laki pertama dari Mangkunegara VII (Kurris, 2009: 63). Ibunya bernama Bendara Raden Ayu Retnoningrum (Selir atau Garwa Ampil) (Suara Karya, September 4,1997). Sang ayah, Mangkunegara VII, memiliki relasi yang sangat baik dengan para intelek Barat untuk menjebatani hubungan antara kebudayaan Barat dan kebudayaan Jawa (Wasino, 2014: 207). Mangkunegara VII sangat terpengaruh dengan gagasan asosiasi yang bertujuan untuk mempertemukan dan menjebatani kebudayaan Barat dan kebudayaan daerah. Mangkunegara VII tercatat sebagai anggota Teosofi yang getol untuk mewujudukan cita-cita dalam gagasan asosiasi (Nugraha, 2011: 80). Ini artinya, Teosofi turut andil untuk mempengaruhi cara pandangnya tentang kebudayaan.

Sang ayah memberi BRM. Saroso pendidikan Jawa dan pendidikan Barat sejak kecil. Ia mengenyam pendidikan dasar di ELS (Europeschee Lagere School) Pasar Legi, Surakarta. Pada 1932, ia melanjutkan studinya di MULO (Middlebaar Uitgebreid Laager Onderwijs). Ia lulus dari MULO pada 1936 (Surabaya Post, September 4, 1987: 5-7). Pada 19 Juni 1937, ia memperoleh gelar Hario sehingga namanya menjadi Kanjeng Pangeran Hario (KPH) Hamijoyo Saroso (Berita Buana, September 5, 1987; (Berita Nasional, September 5, 1987). 
Ia pergi ke Batavia untuk meneruskan studi di AMS (Algemeene Middelbare School) dan tinggal bersama sebuah keluarga Belanda (Kurris, 2009: 63). Ia lulus dari AMS pada 1939. Fakta ini memperlihatkan bahwa ia memiliki kedekatan dengan Belanda karena ia pernah ngenger (menumpang dan mengabdi) pada sebuah keluarga Belanda. Pendidikan ala Eropa mempengaruhi pandangannya tentang dunia yang modern. Meski demikian, ia tetap menjaga tradisi Jawa sehingga ia memadukan modernitas dan tradisionalitas dalam kepemimpinannya.

Mangkunegaran memiliki tradisi kemiliteran yang kental maka setiap pangeran harus mengikuti pendidikan kadet dalam korps Legiun Mangkunegaran. KPH. Saroso mengenyam pendidikan kadet Legiun Mangkunegaran selama satu tahun. Pada 1941, ia mengikuti pendidikan militer Corps Opleiding Voor Reserve Officeren (CORO), sebuah sekolah korps cadangan militer pemerintah Hindia Belanda. Ia sempat melawan pendudukan Jepang hingga Belanda menyerah. Mangkunegaran segera ditetapkan sebagai Kochi oleh Jepang, tetapi Legiun Mangkunegaran dibubarkan. KPH. Saroso memutuskan masuk resimen Pembela Tanah Air (PETA). Sebagai seorang militer, ia diberi bekal oleh resimennya untuk sigap dalam menyusun strategi. Sayangnya, pengalaman dalam bidang militer ternyata tidak membuat ia cakap dalam menghadapi perubahan zaman.

Pada 19 Juli 1944, Mangkunegara VII mangkat. Saroso dinobatkan sebagai penguasa baru Mangkunegaran (Kurris, 2009: 63-64; Basuki, 2010: 58). Ia menjadi penguasa Mangkunegaran dalam masa peralihan kekuasaan dari Jepang ke Republik Indonesia. Ia harus menghadapi gejolak revolusi kemerdekaan dan gerakan anti swapraja yang mengancam eksistensi kepemimpinan Mangkunegara VIII. Meski mengakui Republik Indonesia melalui sebuah surat kawat, ia tidak segera membantu laskar-laskar pejuang dengan otoritas yang dimiliki. Aksi dan reaksi berbeda ditunjukkan oleh Sultan Hamengkubuwana IX yang segera mendukung baik secara moril maupun materiil terhadap perjuangan mempertahankan kemerdekaan Indonesia.

Mangkunegaran menjadi sasaran ketidaksukaan laskar-laskar revolusioner yang anti feodalisme. Pemerintah RI juga menasionalisasi seluruh aset yang dimiliki oleh Mangkunegaran. Mangkunegara VIII kehilangan otoritas politik. Surakarta menjadi basis dari gerakan Tan Malaka Persatuan Perjuangan. Gerakan kiri memperoleh popularitas di Surakarta yang mana meliputi wilayah Kasunanan dan Mangkunegaran. Perbanditan terjadi di wilayah Surakarta. Selama menghadapi gejolak revolusi, Mangkunegara VIII menunjukkan sikap otoriternya.
Sikap tersebut dipengaruhi oleh militerisme. Ini terbukti saat ia menjadi pengageng pura pada masa revolusi. Ia menolak bersatu dengan Sunan dalam suatu sistem pemerintahan directorate. Ia masih ingin mempertahankan otoritasnya sebagai pemimpin DIM. Semua pertemuan yang berkaitan dengan direktorat diboikot olehnya. Ia bersikukuh untuk memegang administrasi sendiri (Kartodirdjo, 1982: 73). Sementara itu, situasi di Surakarta semakin panas. Para gerilyawan dari beberapa kelompok melakukan penculikan kepada beberapa tokoh pemerintah, priayi, dan Sunan sendiri.

Mangkunegara VIII kehilangan otoritas politik dan ekonominya setelah pemerintah Republik mengeluarkan beberapa peraturan yang menghapus otoritas DIM. Dalam sebuah maklumat, pemerintah RI menjadikan para abdi Mangkunegaran sebagai pegawai negeri.

\section{Makloemat 3}

1. Sejak adanya wakil pemerintah Republik Indonesia di Surakarta maka segenap pegawai dari kasunanan maupun dari mangkunegaran adalah menjadi Pegawai Republik Indonesia.

2. Adapun dalam keadaan Negara dalam bahaya sebagai sekarang ini maka Dewan Pertahanan Daerah Surakarta yang dibentuk pada tangal 10 Juni 1946 mempunyai hak-hak dan kewajiban yang tersebut dalam undang-undang keadaan bahaya tanggal 6 Juni 46 No.6

3. Diharap semua pegawai tersebut ayat 1 memenuhi kewajibannya masing-masing dengan penuh kechidmatan dan rasa tanggung jawab terhadap Negara Republik Indonesia (Berkas Catatan Kronologis keadaan di Surakarta terutama masalah pemerintahan antara lain masalah Komisaris Tinggi Direktorium masalah Swapraja, Dewan Pertahanan Daerah, dan lain-lain 1945-1946, 1946).

Arsip tersebut merepresentasikan perintah kepada Mangkunegara VIII untuk merelakan abdinya. Artinya, ia harus kehilangan kekuasaan dan otoritas atas para abdi. Narasi yang dibangun oleh arsip ini memperlihatkan bahwa pemerintah republik ingin agar Mangkunegara VIII tunduk kepada kekuasaan RI. Para abdi tidak lagi harus untuk tunduk kepada Pengageng Pura tetapi tunduk kepada republik. Oleh sebab itu, Mangkunegara VIII melakukan perlawanan secara halus dengan meminta sedikit keringanan agar beberapa jabatan penting Pura memperoleh pengecualian melalui sebuah surat sebagai berikut,

Menurut penetapan Dewan Pertahanan Surakarta yang diumumkan oleh Wakil Divisi Komandan Surakarta pada pagi hari ini di Pendapa MN dan mengin- 
gat keluarnya maklumat dari wakil Pemerintah Pusat di Surakarta tertanggal 14 Mei 1946 angka 3 tentang perubahan pegawai MN menjadi pegawai Republik Indonesia maka perlu kami kemukakan di sini, bahwa di antara pegawai dan jawatan mangkunegaran ada yang hanya perhubungan dengan diri Seri Paduka semata-mata, seperti:

1. Patih Negeri Mangkunegaran

2. Kepeniteraan MN. (Kantor Notoprodjo MN)

3. Kantor urusan Astana (Kabupaten Mandrapura $\mathrm{MN}$ )

4. Kantor Reksopustaka, Pantipustoko dan Sonopustoko (Perpustakaan Seri Paduka)

5. Kantor Reksopustoko, Pantipustaka dan Sonopustoko (Perpustakaan Seri Paduka)

6. Pegawai-pegawai urusan Pesanggrahan dan Makaman.

Pegawai2 dan jawatan2 di atas ini pada hakekatnya tidak dapat dimasukkan dalam keputusan tersebut dan sudah semestinya harus dikecualikan.

Kemudian hendaklah menjadikan tahu adanya (Surat dari Mangkunegaran kepada Panitya Dewan Pertahanan Surakarta Bagian Mangkunegaran di Surakarta, 1946).

Realitas ini menggambarkan bahwa ia mendapat tekanan-tekanan dari pemerintah, kelompok-kelompok laskar, bangsawan moderat, dan masyarakat Surakarta. Situasi ini tentu mempengaruhi kondisi psikis Mangkunegara VIII yang berada dalam tekanan. Oleh sebab itu, pengageng pura berusaha mempertahankan eksistensi dalam ruang kebudayaan Jawa dan membangkitkan kembali kebudayaan khas Mangkunegaran. Sebagaimana pendapat Siburian (2011), revivalisme disebabkan oleh tanggapan terhadap tekanan-tekanan sosial-ekonomi karena modernisasi dan rasionalisasi menyebabkan kecemasan tertentu. Dalam kasus ini, Mangkunegara VIII mengalami kecemasan akibat tekanan-tekanan sosial, politik, dan ekonomi sehingga revivalisme kebudayaan Jawa menjadi obat untuk mengatasinya.

\section{Membangun Revivalisme Kebudayaan Jawa}

Diskursus revivalisme kebudayaan Jawa adalah konstruksi pengetahuan tentang kebangkitan kembali kebudayaan Jawa yang disebarluaskan melalui praktik-praktik tertentu sehingga mengandung suatu jaringan kuasa. Menurut Puguh (2015), kebudayaan Jawa mengalami kebangkitan pasca kemerdekaan Indonesia yang ditandai dengan tumbuhnya berbagai macam lembaga pengembangan kebudayaan di Surakarta. Diskursus inilah yang dimanfaatkan oleh Mangkunegara VIII untuk menghadapi tekanantekanan sosial, ekonomi, dan politik.

Dalam sebuah diskursus, terdapat suatu episteme. Episteme berhubungan dengan penyimpangan-peny- impangan, jarak-jarak, perlawanan-perlawanan, perbedaan-perbedaan, dan relasi-relasi dari berbagai diskursus-diskursus keilmiahan. Ia berpendapat bahwa episteme adalah himpunan yang kompleks dari hubungan antara pengetahuan yang dihasilkan pada periode tertentu dan sistem regulasi sehingga menghasilkan pengetahuan. Pergerakan dari satu episteme ke episteme lainnya mempengaruhi keterputusan diskursif atau diskontinuitas baru (Mills, 2003: 6264). Jadi, episteme merupakan seluruh kompleksitas dan kerumitan sistem yang menentukan terbentuknya pengetahuan pada kurun historis tertentu.

Jika masa Mangkunegara VII diskursus revivalisme kebudayaan Jawa adalah tanggapan atas kompleksitas relasi kolonialisme, modernitas, dan Islamisme, maka pada masa Mangkunegara VIII memiliki episteme yang berbeda. Pada masa Mangkunegara VIII, ada diskursus anti feodalisme, anti swapraja, dekolonialisme, nasionalisme, komunisme, sosialisme, modernitas, dan kebudayaan nasional yang berkembang dan membentuk suatu episteme. Inilah yang mempengaruhi Mangkunegara VIII untuk merevivalisasi kebudayaan Jawa. Ia membangun diskursus dan menyebarkannya melalui berbagai media, salah satunya melalui organisasi kekerabatan.

Pada 1946, Mangkunegara VIII mendirikan Himpunan Kerabat Mangkunegaran (HKMN). Anggaran Dasar organisasi ini disahkan pada 1950, tetapi mengalami beberapa perubahan pada 1970 . Tujuan lembaga ini adalah menyatukan kerabat Mangkunegaran demi nusa dan bangsa dalam perjuangan kemerdekaan Indonesia. Artinya, selama masa revolusi pasca kemerdekaan Indonesia, kerabat Mangkunegaran memiliki perbedaan visi dan misi. Ada golongan moderat yang menginginkan perubahan terhadap struktur birokraasi tradisional tetapi tetap mempertahankan pemerintahan Praja. Ada pula golongan konservatif yang mempertahankan keistimewaan pemerintahan Praja Mangkunegaran dalam sebuah Daerah Istimewa Mangkunegaran. Perbedaan-perbedaan pandangan ini memiliki potensi untuk memicu suatu konflik keluarga. Oleh sebab itu, HKMN menjadi media untuk menghindari konflik antar kerabat Mangkunegaran dan menghadapi masalah penghapusan otoritas Mangkunegaran sebagai sebuah praja. Selain itu, beberapa pihak menuding bahwa Mangkunegara VIII memihak Belanda sehingga ia perlu membangun diskursus "dalam perjuangan kemerdekaan Indonesia" pada tujuan HKMN. Teks ini ingin mencitrakan bahwa Mangkunegaran pro-republik atau tidak seperti anggapan oposisi dan pemerintah RI. Meskipun fakta historis menunjukkan bahwa Mangkunegara VIII pernah mengambil alih aset-aset yang sudah dinasionalisasi oleh Pemerintah Republik saat aksi polisionil (Agresi Militer) Belan- 
da. Dengan kata lain, ia pernah memihak Belanda sebelum mendapat tekanan untuk mendukung Republik Indonesia yang dibuktikan dalam Konferensi Meja Bundar 1949. Oleh sebab itu, organisasi ini penting untuk konsolidasi internal Mangkunegaran dalam menghadapi situasi politik nasional. Selain HKMN, Mangkunegaran juga memiliki perkumpulan lainnya. Ada perkumpulan untuk mewadahi para pemuda Mangkunegaran, yaitu Himpunan Pemuda Mangkunegaran (HPMN). Kemudian, Himpunan Wanita Mangkunegaran (HWMN) menjadi organisasi kaum perempuan Mangkunegaran. Oleh sebab itu, Mangkunegaran memiliki tiga perangkat organisasi yang mewadahi para pria, pemuda, dan perempuan Mangkunegaran (Pengetan 40 Tahun Jumenengdhalem S.I.J. Mangkoenagoro VIII Hing Surakarta Surya kaping 19 Juli 1984 ing Pandhapi Ageng Mangkunegaran, 1984). HPMN adalah organisasi yang mempersiapkan generasi penerus Mangkunegaran. HWMN menjadi organisasi yang menghimpun kegiatan para perempuan untuk melestarikan adat, tradisi, dan kesenian Mangkunegaran. Melalui ketiga organisasi ini, Mangkunegara VIII memiliki motivasi tindakan agar seluruh kerabat Mangkunegaran tunduk pada seluruh perintahnya sebagai kepala trah Mangkunegaran dan mencitrakan keberpihakan pada Republik.

Organisasi-organisasi ini juga digunakan oleh Mangkunegara VIII untuk menyebarluaskan diskursus kebudayaan Jawa melalui program-program kebudayaan. Saat HKMN mendapat tambahan nama Suryasumirat, organisasi ini memiliki tujuan sebagai wadah pelestarian budaya khas Mangkunegaran khususnya kesenian, pengembangan pariwisata, dan pendukung pembangunan nasional. Selain HKMN, masalah pengembangan kebudayaan diurusi oleh Langenpraja, sebuah lembaga pengelola hiburan dan kesenian yang berdiri sejak 1867 (Harmanto, 1997). Pada masa Mangkunegara IV, lembaga ini berada di bawah Kawedanan Reksawitana, tetapi Mangkunegara VIII memasukkannya ke golongan Panti Boedaja Mangkunegaran pada masa Republik (Surat Mangkunegara VIII kepada Pengurus RRI Surakarta bagian Siaran, 1947). Melalui lembaga-lembaga ini, kesenian Mangkunegaran dipertujukkan kepada masyarakat dan elite politik nasional. Mangkunegara VIII sering menyumbangkan kesenian khas Mangkunegaran.

Ia pernah menyumbangkan pertunjukan Langendriyan, tari Golek, dan Fragmen Handaga-Bugis kepada Kongres Ikatan Perwira Republik Indonesia. Booklet mengenai kesenian khas Mangkunegaran dibagikan kepada para peserta. Satu hal menarik dalam buku kecil tersebut adalah sebuah teks bertuliskan "Ukuran Tinggi Rendahnya suatu Bangsa ialah: Kebudayaan". Artinya, Mangkunegara VIII ingin memperlihatkan arti penting kebudayaan Mangkunegaran bagi negara dan bangsa Indonesia melalui pertunjukan seni. Mangkunegara VIII ingin memperlihatkan bahwa setiap seni pertunjukan Mangkunegaran mengandung nilai-nilai budaya Jawa yang dapat dihayati. Itulah sebabnya, ia memilih tari golek (boneka perempuan) yang menggambarkan kebiasaan remaja putri Jawa, fragmen Handaga-Bugis sebagai simbol persengketaan antar penguasa, dan Langendriyan sebagai simbol kemenangan kebaikan (Damarwulan) terhadap angkara murka (Menak Jinggo).

Mangkunegara VIII menyebarluaskan pengetahuan tentang nilai luhur kebudayaan Jawa, sebagaimana dalam kutipan berikut:

Pemain-pemain tari, njanjian dan gamelan semua jang terpilih dari Mangkunegaran menghidangkan suatu kesenian Indonesia asli jang tinggi nilaija. Inilah satu-satunja Kebudajaan Indonesia peninggalan dari nenek-mojang sedjak zaman Sriwidjaja, Madjapahit, hingga sekarang masih tjemerlang, tinggi mutunja; menundjukkan betapa tinggi dan luhur mertabat Bangsa Indonesia. Meski bagaimana arus kebudajaan asing, terutama Barat, datang menerdjang, seakan-akan mendesak, hendak mengenjahkan Kebudajaan kita, namun ia tetap tegak teguh bagaikan batu karang jang berabad-abad diterdjang gelombang dahsjat (Pertundjukan Kesenian Istimewa Sumbangan dari S.P Mangkunegara VIII kepada Panitya Konggres Ikatan Perwira Republik Indonesia, 1950).

Teks di atas merupakan sebuah narasi yang dibangun oleh Mangkunegara VIII untuk menunjukkan bahwa kesenian Mangkunegaran merupakan kesenian "asli" Indonesia. Kata "asli" merupakan sebuah diskursus untuk menguatkan citra Mangkunegaran sebagai pusat kebudayaan Jawa. Ini karena kebudayaan Jawa sebenarnya terbuka terhadap pengaruh-pengaruh yang berasal dari luar tetapi tetap dapat mempertahankan kekhasannya. Mangkunegaran memiliki peran penting dalam pelestarian dan pengembangan kebudayaan Jawa.

Narasi kegemilangan kerajaan-kerajaan Sriwijaya dan Majapahit menunjukkan keabsahan Mangkunegaran sebagai pewaris kekayaan budaya kerajaan-kerajaan tersebut. Terlebih lagi, narasi tersebut didahului oleh kata-kata, "inilah satu-satunya Kebudayaan Indonesia" yang memperlihatkan keunggulan dan kekhasan Mangkunegaran. Peran penting Mangkunegaran sebagai penjaga kebudayaan Jawa digambarkan melalui narasi tentang penetrasi kebudayaan Barat yang menggerogoti kebudayaan Jawa. Narasi ini menguatkan kisah yang terkandung dalam fragmen Langendriyan. Secara jelas, Mangkunegara VIII memilih Langendriyan yang mengambil kisah 
tentang Majapahit untuk membangkitkan kenangan kejayaan masa lampau.

Pada kesempatan lain, ia pernah menyumbangkan kesenian Langendriyan khas Mangkunegaran dalam jamuan Perayaan Perkawinan puteri Prof. M. Soetojo di Simpangse Societeit Surabaya pada 25 Mei 1957. Booklet pertunjukan menceritakan tentang deskripsi Langedriyan dan sinopsis kisah fragmen yang dipertunjukkan. Booklet juga menjelaskan bahwa Langendriyan adalah kesenian khas Mangkunegaran sebagai berikut.

Sebagai pengantar kata, diterangkan di sini bahwa Langendrija jang biasa dipertundjukkan di Istana Magkunegaran, adalah sematjam pertundjukan Opera bagi orang Eropa, ialah: bangsa Barat pada umumnja. Pemain2-nja mendjalankan peranan dalam pertundjukan ini, kesemuanja dilakukan oleh wanita, djuga peranan jg. mestinja dilakukan oleh prija, dilakukan oleh wanita djuga. Ini semua perlu untuk menjelaraskan melodi (lagu2) dengan suara dan gending2 dalam gamelan jang dibunjikan (Langendrija Pertundjukan Fragmen Langendrijan Mangkoenagaran Surakarta untuk djamuan perajaan Perkawinan puteri dari Prof. M. Soetojo, 1957).

Berdasarkan petikan booklet di atas, ada pengetahuan yang diperoleh oleh penonton. Pengetahuan bahwa langendriyan adalah kesenian khas Mangkunegaran yang mirip seperti Opera dalam kebudayaan Eropa. Lagu yang didendangkan adalah tembang Jawa yang diiringi oleh musik gamelan Jawa. Sebagaimana Haryono (2012) menjelaskan, kesenian ini merupakan opera Jawa yang memadukan komponen verbal, yaitu tembang macapat dan komponen non verbal, yaitu musik, tari, tata rias, dan properti pendukung. Kesenian ini mengisahkan tentang kisah Panji-Raden Damarwulan berlatarbelakang zaman Majapahit. Semua peran baik laki-laki maupun perempuan yang ada dalam kesenian ini dilakukan oleh perempuan. Pertunjukannya dilakukan dengan berdiri. Inilah kekhasan yang dimiliki oleh Mangkunegaran karena Langendriyan Yogyakarta dilakukan oleh laki-laki dan dilakukan dengan sikap jengkeng (Widyastutieningrum, 2006: 1-2).

Membangkitkan Langendriyan Mangkunegaran memiliki dampak yang signifikan bagi kesadaran subjek. Seorang pejabat pemerintah, Menteri Pembangunan Masyarakat Desa yang menjabat pada 1965, Ipik Gandamana, berusaha untuk meyakinkan Mangkunegara VIII agar bersedia mendokumentasikan Fragmen Langendriyan.

Berikut adalah suratnya kepada Mangkunegara VIII, ...Adalah tidak dikehendaki apabila langendrijan sebagai permata kebudayaan (kunstschat) jang mend- jadi milik kebanggaan kita itu sampai terlupakan sehingga kita selalu berkeinginan untuk dapat menemukannja kembali, kemudian dapat mengetengahkannja kepada masjarakat bangsa kita dengan para penggemarnja sehingga dengan demikan tetap hidup dalam kepertjajaan kebudajaan bangsa kita.

Untuk maksud tersebut saja berpendapat bahwa kita dapat menemukannja terutama dengan adanja petundjuk-petundjuk dan bantuan jang tidak ternilai dari Sri Paduka.

Adalah sangat serasi apabila dalam penjelenggaraannja jang selengkapnja dengan bantuan dari Sri Paduka dapat digunakan gamelan Kjahi Kanjut Mesem jang ada pada Mangkunegaran dan dibawakan oleh para waranggono (biduanita) jang terdahulu jang sekarang masih ada, ditambah dengan seniwati-seniwati jang sekarang.

Saja berkejakinan bahwa RRI Djakarta dan RRI Solo bersama-sama dengan Lokananta akan bersedia mengusahakan perekamannja dengan mengeluarkan piringan hitamnja, sehingga dengan demikian Langendrijan sebagai pusaka perbendaharaan kebudajaan tetap hidup dan terpelihara di tengah-tengah kita.

Dalam hubungannja dengan inilah maka pada bulan jang lalu saja telah menugaskan Sdr. Brigdjen Soedarmo Pembantu Menteri Pembangunan Masjarakat Desa Urusan Umum Bersama-sama dengan Sdr. Soeprapto dari RRI Djakarta untuk meneliti kemungkinan-kemungkinan usaha-usaha tersebut (Surat dari Menteri Pembangunan Masjarakat Desa, Ipik Gandamana kepada Sri Paduka Mangkunegoro di Solo, 1965).

Berdasarkan arsip di atas, Ipik Gandamana pernah menyaksikan pementasan Langendriyan Mandraswara khas Mangkunegaran sehingga memiliki rasa ketertarikan terhadap kesenian tersebut. Setelah terpesona, Gandamana mengajukan permohonan kepada Mangkunegara VIII agar Langendriyan dapat didokumentasikan oleh negara melalui RRI Surakarta dan Lokananta. Usul tersebut merupakan sebuah keseriusan sang menteri. Pemerintah Keresidenan Surakarta memfasilitasi pertemuan antara pihak Mangkunegaran dengan Residen Surakarta, Kepala Studio RRI Surakarta, dan Direksi Lokananta (Berkas tentang Rencana Perekaman Langendriyan Mangkunegaran, 1965). Uniknya, usul ini bukan berasal dari Menteri Pendidikan dan Kebudayaan, tetapi disampaikan oleh seorang Menteri Pembangunan Masyarakat Desa. Artinya, penyebarlasan diskursus melalui pertunjukan seni khas Mangkunegaran berhasil mempengaruhi pikiran sadar dan bawah sadar sang menteri. Oleh sebab itu, menteri yang tidak 
mengurusi dalam bidang kebudayaan bisa memiliki keinginan untuk mendokumentasikan, padahal seharusnya usul tersebut dilontarkan oleh Menteri Kebudayaan.

Sementara itu, pengaruh kesenian khas Mangkunegaran ini sangat kental dalam pengembangan kesenian tradisional di luar istana. Buktinya, S. Maridi, maestro tari Surakarta, mengkreasi Langendriyan berdasar pada Langendriyan Mangkunegaran pada 1972. Kemudian, ia bersama Sutjiati Djoko Suhardjo menyusun Langendriyan yang diperankan laki-laki dan perempuan pada 1974. Himpunan Wanita Mangkunegaran (HWMN) menggubah Langendriyan dengan mengurangi jumlah pupuh tembang, mengurangi gendhing iringan, merubah susunan tari, dan mengubah peran penari (penari hanya menari karena lagu dinyanyikan oleh waranggana atau pesindhen).

Sekolah Menengah Karawitan Indonesia Surakarta juga menjadikan Langendriyan Mangkunegaran sebagai materi pelajaran, tetapi pemeran dilakukan oleh siswa laki-laki dan perempuan. Seniman Surakarta seperti Wahyu Santosa Prabowo dan Nora Kustantina Dewi juga mengkreasi Langendriyan Mangkunegaran dengan merubah gerak tari, menggunakan antawecana, dan menampilkan pemeran sesuai tokoh (Widyastutieningrum, 2006: 2-3). Kreasi-kreasi ini memperlihatkan keberhasilan Mangkunegara VIII dalam bidang kebudayaan sehingga mempengaruhi kehidupan kesenian di Surakarta. Langendriyan bukan satu-satunya jenis seni pertunjukan yang mempengaruhi kreasi seni tradisi di Surakarta.

Berdasarkan pendapat Puguh, Mangkunegara VIII meneguhkan identitas Mangkunegaran dalam sebuah tarian pasca kemerdekaan. Tarian itu adalah Gambyong Pareanom. Gambyong adalah sejenis tari taledhek (tayub), erotis, dan simbol kesuburan yang mengalami penghalusan sehingga dapat ditampilkan di istana. Citra Suharya, Nyi Bei Mintararas, dan Rana Suripta adalah ahli kesenian Mangkunegaran yang mengeksekusi keinginan Mangkunegara VIII untuk membakukan struktur gerak Gambyong versi "baru" pada zaman itu (Puguh, 2015: 457-464). Gambyong Pareanom menjadi sebuah tarian estetis dan erotis simbol Mangkunegaran.

Gambyong sebagai tari yang bersifat estetis dan erotis terus dikembangkan oleh seniman istana pada masa Mangkunegara VIII. Ada Gambyong Sumyar atau Campursari karya Mintararas dan Gambyong Retna Kusuma atau Ndut-ndut. Gambyong khas Mangkunegaran mempengaruhi para seniman Surakarta sehingga mereka mengkreasi Gambyong berdasarkan Gambyong Pareanom khas Mangkunegaran. Gambyong menjadi tari yang sering disajikan di berbagai macam acara sepeti pentas seni, pernikahan, dan penyambutan tamu di luar tembok istana. Artinya, Gambyong berhasil menjadi media penyemai diskursus untuk mencitrakan Mangkunegaran sebagai pusat pengembangan dan pelestarian kesenian istana yang merakyat. Selain itu, Mangkunegara VIII juga menggali kesenian istana yang mengalami mati suri. Bedhaya Anglir Mendhung merupakan salah satu kesenian sakral milik istana Mangkunegaran yang digali oleh para maestro Mangkunegaran. Beksan ini diciptakan oleh Mangkunegara I pada abad ke-18. Para penggali menggunakan manuskrip Jawa yang tersimpan di Perpustakaan Reksa Pustaka Mangkunegaran. Mangkunegaran juga melakukan ritual untuk memuliakan sesepuh yang berperan penting dalam penciptaan Gendhing Anglir Mendhung, Kyai Demang Secakarma dan Kyai Rangga Kidangwangi (Kidangwulung) (Beksan Anglir Mendhung Nyarengi Pengetan Wiyosandalem jangkep yuswa 64 Tahun, 1982). Mereka juga mengeluarkan sesaji sebagai ungkapan syukur dan keselamatan bersamaan dengan pementasan yang terdiri dari ketan biru, eten-eten, jajan pasar, bekakak, nasi megana, nasi asahan, nasi golong, sekar setaman, sekar uteran lima warna (kanthil, kenanga, mlathi, mawar merah, dan putih) (Jaya Baya, Januari 24, 1982).

Pada Desember 1981, TVRI Jakarta dan Yogyakarta mendokumentasikan pementasan Gendhing Anglir Mendhung dan beksan yang ditampilkan oleh tiga penari. Pada jumenengan dalem KGPAA Mangkunegara VIII Februari 1982 dan pengetan khol dalem KGPAA Mangkunegara I, beksan ini disajikan lagi oleh tiga penari Mangkunegaran (Jaya Baya, Januari 24, 1982). Namun, pada peringatan ulang tahun penobatan Mangkunegara VIII 19 Juli 1987, beksan disajikan oleh tujuh orang penari bukan tiga (Suara Merdeka, 19 Juli 1987). Artinya, Mangkunegaran memerlukan waktu beberapa tahun untuk menampilkan beksan yang benar-benar sesuai dengan masa awal. Ini mengindikasikan bahwa para penggali menghadapi kesulitan-kesulitan disebabkan oleh keterbatasan sumber dan penemuan sumber baru. Ini juga menunjukkan keseriusan Mangkunegaran untuk menghidupkan kembali "pusaka Langenpraja." Oleh sebab itu, ada motivasi tertentu di balik penggalian beksan ini karena setiap praktik budaya pasti mengandung maksud tersembunyi.

Bedhaya Anglir Mendhung adalah simbol kejayaan Mangkunegara I. Kisah yang dituturkan melalui beksan sakral tersebut adalah kepahlawanan R.M Said (Mangkunegara I) yang terkenal dengan panji perang Sambernyawa di medan perang. Oleh sebab itu, para penari mengenakan perlengkapan tari, yaitu pistol pada versi tiga penari; busur dan panah pada versi tujuh penari. Para penari juga membuat formasi perang seperti Makarabyuha, Kagapati, Tiksna Bajrabyuha, 
cakra swandana, emprit neba, dan beberapa formasi lainnya seperti yang digunakan oleh R.M Said di medan perang. Narasi ini tidak hanya dibangun melalui sajian beksan kepada khalayak, tetapi juga mempengaruhi media cetak sebagai berikut,

Namun yang paling diagungkan dan dianggap keramat, bahkan dilestarikan hingga kini adalah Beksan Bedhoyo Anglir Mendhung, menggambarkan kepahlawanan Pangeran Sambernyowo di palagan Kasatriyan itu. Konon Gendhing Anglir Mendhung, baik bentuk maupun iramanya, tak ubahnya dengan gendhing Gadhungmlathi ciptaan Sultan Agung Hangrokokusumo Mataram. Bahkan menurut RT Warsodiningrat, empu gendhing kamyagan Karaton Surakarta (PB-X hingga PB-XII), gendhing Gadhungmlathi ini dari pemberian Kanjeng Ratu Kanconosari yakni Ratu Kidul. Konon gendhing pusaka yang besar tuahnya untuk kedamaian, kemakmuran dan kejayaan praja dan kawulanya. Itulah sebabnya PA Mangkunegoro dalam mencipta Beksan Bedhaya Anglir Mendhung sengaja menyerap hikmah gendhing pusaka itu ke dalam 3 bait Sekar Durmo yang mengawali Ketawang Kemanak Anglir Mendhung... (Suara Merdeka, Juli 19, 1987).

Berdasarkan formasi-formasi diskursif di atas, tindakan budaya melalui penggalian, penyajian, dan narasi beksan Bedhaya Anglir Mendhung adalah upayanya untuk menyebarluaskan pengetahuan sebagai pengayom kebudayaan Jawa. Mangkunegara VIII memiliki motif untuk mempengaruhi kesadaran dan ketidaksadaran subjek. Narasi kebesaran Mangkunegara I dalam beksan diproduksi olehnya sebagai sarana untuk memperkuat hegemoni kebudayaan dari para abdi, masyarakat umum, dan pemerintah. Itulah sebabnya, ia membangun pengetahuan yang memiliki relasi kuasa di balik wacana "harta Langenpraja Mangkunegaran". Sebagaimana Armstrong (2015) menganalisis pernyataan Foucault, pengetahuan tidak dapat dilepaskan dari kekuasaan karena merupakan sebuah asosiasi antara jalan mengetahui masyarakat dan cara memperlakukan mereka. Artinya, pengetahuan dan kekuasaan memiliki kaitan erat untuk mempengaruhi subjek, yaitu masyarakat. Dalam kasus ini, subjeknya adalah para abdi, masyarakat, dan pemerintah.

Mereka merupakan subjek yang terhegemoni oleh diskursus revivalisme kebudayaan Jawa Mangkunegara VIII. Artinya, fungsi diskursus tersebut adalah mempengaruhi subjek agar Mangkunegara VIII dapat memperoleh kuasa atas kebudayaan Jawa. Misalnya saja, pada masa pemerintahan Presiden Sukarno, Lembaga Kebudayaan Rakyat (Lekra) yang disebut-sebut oleh pemerintah Orde Baru sebagai onderbouw Partai Komunis Indonesia (PKI), pernah meminta Mangkunegara VIII untuk menjadi Ketua
Kehormatan Kongres Lekra I di Surakarta (Surat Panitia Konggres Nasional Ke I Lekra kepada Sri Paduka Mangkunegoro ke VIII, 1958). Secara ideologis, Lekra kurang menyukai feodalisme karena membangun wacana seni untuk rakyat, realisme sosialis, dan ideologi dalam berkesenian. Mangkunegaran pernah menjadi sasaran gerakan anti feodalisme pada masa revolusi. Ini berarti, Lekra memandang bahwa Mangkunegara VIII adalah sosok penting dalam kebudayaan Jawa yang dapat mempengaruhi rakyat. Kemudian, pada masa Orde Baru, Mangkunegara VIII adalah anggota Golkar sehingga ia diangkat oleh partai untuk menjadi juru kampanye. Golkar tentu menganggap bahwa Mangkunegara VIII masih memiliki power sehingga dapat mempengaruhi pilihan rakyat di Surakarta.

Realitas ini selaras dengan pendapat Gramsci (dalam Hoare \& Smith (ed), 1992: xiv), hegemoni merupakan sebuah fase historis untuk memperoleh ketundukan melalui konsensus atau persetujuan sadar. Dengan demikian, makna diskursus revivalisme kebudayaan Jawa Mangkunegara VIII bagi subjek adalah Mangkunegaran sebagai pusat pengetahuan dan lembaga pelestarian kebudayaan Jawa. Mangkunegaran dianggap oleh mereka sebagai pusat pembangkit kesenian-kesenian Jawa yang sudah mengalami mati suri. Kesenian khas Mangkunegaran menjadi inspirasi dalam penciptaan dan kreasi seni oleh para seniman tradisonal. Mereka menganggap bahwa mangkunegaran merupakan benteng kebudayaan dari penetrasi kebudayaan asing. Realitas ini adalah bukti keberhasilan hegemoni Mangkunegara VIII dalam bidang budaya di tengah keterbatasan dan perubahan zaman.

\section{SIMPULAN}

Mangkunegara VIII adalah kepala trah Mangkunegaran yang memimpin di era republik. Gejolak politik pasca kemerdekaan Indonesia menghimpit posisinya sebagai penguasa. Ia kehilangan kedudukan sebagai penguasa praja sehingga hanya menjadi pengageng pura yang tidak punya kekuasaan untuk memerintah layaknya seorang kepala pemerintahan. Ia menerima berbagai macam tekanan sosial, politik, dan ekonomi. Oleh sebab itu, ia membutuhkan kebudayaan Jawa khas Mangkunegaran untuk mempertahankan kehormatannya. Ia membangun diskursus revivalisme kebudayaan Jawa.

Wacana revivalisme kebudayaan Jawa Mangkunegara VIII berbentuk klaim bahwa ia adalah pengayom kebudayaan Jawa. Mangkunegaran merupakan pusat pelestarian kebudayaan Jawa. Mangkunegaran mempertunjukkan kesenian-kesenian khasnya kepada khalayak umum, para pejabat, dan tamu-tamu asing. Mangkunegaran menjadi pusat untuk menggali 
kesenian-kesenian khasnya yang pernah mati suri. Fungsi dari wacana ini adalah untuk memperoleh kehormatan dari abdi dalem, masyarakat, dan petinggi republik dalam bidang kebudayaan. Makna dari wacana ini bagi mereka yang terhegemoni adalah anggapan bahwa Mangkunegaran menyimpan harta dan warisan budaya yang adiluhung dari para leluhur.

\section{DAFTAR RUJUKAN}

Al-Azmeh, A. (1991). Islamist Revivalism and Western Ideologies. History Workshop, 32, 44-53. Diakses dari http://www.jstor.org/stable/4289100

Anonim. (1982). Beksan Anglir Mendhung Nyarengi Pengetan Wiyosandalem jangkep yuswa 64 Tahun. Koleksi Reksopustaka Mangkunegaran

Armstrong, P. (2015). The discourse of Michel Foucault: A sociological encounter. Critical Perspectives on Accounting, 27, 29-42. doi:http://dx.doi. org/10.1016/j.cpa.2013.10.009

Barker, C., \& Galasiński, D. (2001). Cultural Studies and Discourse Analysis: A Dialogue on Language and Identity. London, Thousand Oaks, \& New Delhi: SAGE Publications.

Basuki, A. R. (2010). Peranan Komisi Dana Milik Mangkunegaran dalam Proses Nasionalisasi Asetaset Mangkunegaran Tahun 1946-1952. Surakarta: Skripsi, Ilmu Sejarah, FSSR, Universitas Sebelas Maret.

Berita Buana (September 5, 1987).

Berita Nasional (September 5, 1987).

Curtis, H. D. (2011). A Sane Gospel: Radical Evangelicals, Psychology, and Pentecostal Revival in the Early Twentieth Century. Religion and American Culture: A Journal of Interpretation, 21(2), 195-226. doi:10.1525/rac.2011.21.2.195

Davidson, J. S., \& Henley, D. (2007). The Revival of Tradition in Indonesian Politics The deployment of Adat from Colonialism to Indigenism. Oxon, New York: Routledge.

Evers, H. D., \& Siddique, S. (1993, Februari). Religious Revivalism in Southeast Asia: An Introduction. 8(1), 1-10. Diakses dari http://www.jstor.org/ stable/41035725
Fakih, F. (2014). Akar-akar Kanan daripada Nasionalisme Indonesia: Nasionalisme Jawa dalam Konteks Kesejarahannya. Lembaran Sejarah, 11(1).

Gramsci, A. (1992). Selections From the Prison Notebooks, ed. Q Hoare dan G. Nowell-Smith. New York: INTERNATIONAL PUBLISHERS.

Greeley, A. (1994, September). A Religious Revival in Russia? Journal for the Scientific Study of Religion, 33(3), 253-272. Diakses dari http://www.jstor. org/stable/1386689

Haryono, S. (2012, Januari - Maret). Implementasi Konsep Langendriya Mandraswara terhadap Seniman Muda. Jurnal Seni \& Budaya Panggung, 22 (1), $94-106$.

Jaya Baya. (1982, Januari 24). Nglacak Baline Anglir Mendhung Sambernyawan. Jaya Baya.

Kartodirdjo, S. (1982). Revolution in Surakarta 1945-50: A Case Study of City and Village in the Indonesian Revolution. Canberra: Thesis of The Australian National University.

Kurris, R. (2009). Purbayan di Tengah Rakyat dan Ningrat. Surakarta: ARAYA.

Magnis-Suseno, F. (1984). Etika Jawa: Sebuah Analisa Falsafi tentang Kebijaksanaan Hidup Jawa. Jakarta: PT. Gramedia.

Mangkunegaran. (1984). Pengetan 40 Tahun Jumenengdhalem S.I.J. Mangkoenagoro VIII Hing Surakarta Surya kaping 19 Juli 1984 ing Pandhapi Ageng Mangkunegaran. Koleksi Rekso Pustaka Mangkunegaran

Maxwell, D. (2018, April ). Continuity and Change in the Luba Christian Movement, Katanga, Belgian Congo, c. 1915-50. Journal of Ecclesiastical History, 69(2), 326-344. doi:10.1017/S0022046917000720

McGregor, J. (2012). Rethinking detention and deportability: Removal centres as spaces of religious revival. Political Geography, 31, 236-246. doi:10.1016/j.polgeo.2012.03.003

Meyer. (2011). Falling for the Lord Shame, Revivalism, and the Origins of the Second Great Awakening. Early American Studies: An Interdisciplinary Journal, 9(1), 142-166. doi:10.1353/eam.2011.0002 
Mode, P. G. (1921, Juli). Revivalism as a Phase of Frontier Life. The Journal of Religion, 1(4), 337-354. Diakses dari http://www.jstor.org/stable/1195154

Mudzakkir, A. (2011). Revivalisme Masyarakat Adat dalam Politik Lokal di Indonesia Pasca-Soeharto: Studi Kasus Komunitas Kampung Naga, Tasikmalaya, Jawa Barat. Volume 13 No. 1, 167-184.

Müller, T., \& Neundorf, A. (2012, Desember ). The Role of the State in the Repression and Revival of Religiosity in Central Eastern Europe. Social Forces, 91(2), 559-582. doi:10.1093/sf/sos142

Northmore-Ball, K., \& Evans, G. (2016). Secularization versus religious revival in Eastern Europe: Church institutional resilience, state repression and divergent paths. Social Science Research, 57, 31-48. doi:http:// dx.doi.org/10.1016/j.ssresearch.2015.11.001

Nugraha, I. P. (2011). Teosofi, Nasionalisme dan Elite Modern Indonesia. Jakarta: Komunitas Bambu.

Panikkar, K. N. (2003, Februari). Colonialism, Culture and Revivalism. Social Scientist, 31(1/2), 3-16. Diakses dari http://www.jstor.org/stable/3518287

Puguh, D. R. (2015). “Mengagungkan Kembali Seni Pertunjukan Tradisi Keraton: Politik Kebudayaan Jawa Surakarta, 1950-an-1990-an”. Disertasi: Program Pasca Sarjana Fakultas Ilmu Budaya Universitas Gadjah Mada.

Ratna, N. K. (2010). Metodologi Penelitian Kajian Budaya dan Ilmu Sosial Humaniora Pada Umumnya . Yogyakarta: PUSTAKA PELAJAR.

Ritchie, D. (2014, October). William Mcllwaine and the 1859 Revival in Ulster: A Study of Anglican and Evangelical Identities. Journal of Ecclesiastical History, 65(4), 803-826. doi:10.1017/ S002046913000602

Siburian, E. P. (2011). Perjalanan Hidup dan Upaya Membangkitkan Kembali Seni Opera Batak Tilhang Serindo.

Suara Karya, September 4, 1997

Surabaya Post (September 4, 1987).

Surat Panitia Konggres Nasional Ke-I Lekra kepada Sri Paduka Mangkunegoro ke VIII. (1958). Koleksi Reksa Pustaka Mangkunegaran.
Wasino. (2014). Modernisasi di Jantung Budaya Jawa: Mangkunegaran 1896-1944. Jakarta: Penerbit Buku Kompas.

Weiss, G., \& Wodak, R. (2003). Critical discourse analysis: theory and interdisciplinarity. Hampshire and New York: PALGRAVE MACMILLAN.

Widyastutieningrum, S. R. (2006). Langendriyan Mangkunegaran: Pembentukan dan Perkembangan Bentuk Penyajiannya. Surakarta: ISI Press. 